\title{
Les fondements métallurgiques du yahwisme israélite
}

\section{Nissim Amzallag}

\section{(2) OpenEdition \\ 1 Journals}

Édition électronique

URL : https://journals.openedition.org/annuaire-cdf/16314

DOI : 10.4000/annuaire-cdf.16314

ISBN : 978-2-7226-0572-5

ISSN : 2109-9227

Éditeur

Collège de France

Édition imprimée

Date de publication : 30 décembre 2020

Pagination : 687-688

ISBN : 978-2-7226-0516-9

ISSN : 0069-5580

\section{Référence électronique}

Nissim Amzallag, "Les fondements métallurgiques du yahwisme israélite », L'annuaire du Collège de

France [En ligne], 118 | 2020, mis en ligne le 01 avril 2021, consulté le 22 août 2022. URL : http:// journals.openedition.org/annuaire-cdf/16314; DOI : https://doi.org/10.4000/annuaire-cdf.16314 


\title{
LES FONDEMENTS MÉTALLURGIQUES DU YAHWISME ISRAÉLITE
}

\author{
Nissim AMZALLAG
}

Chercheur à Ben Gurion University, Beer Sgeba (Israël)

Mots-clés : Israël, yahvisme

Conférence prononcée le 16 mai 2018 (invitation sur proposition du $\mathrm{Pr}$ Thomas Römer).

Les attestations bibliques quant à une origine sud-désertique (Arabah, Negeb, Sinai) de YHWH ont trouvé ces dernières décennies un support dans certaines découvertes archéologiques, notamment à Kuntillet Ajrdud et dans la vallée du Nil. C'est pourquoi une origine qénite-midianite-édomite du dieu d'Israël est maintenant solidement fondée. Par ailleurs, de récentes fouilles menées dans l'Arabah y ont révélé une reprise intense de l'activité métallurgique (production de cuivre) à partir de la fin du second millénaire avant notre ère, l'époque où, justement, les premières attestations d'Israël voient le jour. Or deux indications laissent entrevoir une possible relation entre ces observations. Tout d'abord, les Qénites, les premiers adorateurs de YHWH mentionnés dans la Bible, sont identifiables comme métallurgistes, tant par leur appellation, par la généalogie de Caïn, que par certaines allusions quant à leur activité. Ensuite, l'identité du dieu patronnant la production de cuivre dans l'Arabah, dont l'importance économique ne saurait être exagérée dans les régions désertiques du Sud-Levant, n'est pas connue aujourd'hui. Cela invite à examiner sérieusement l'hypothèse de fondements métallurgiques au Yahwisme pré-israélite et d'une nature ésotérique de son culte. L'idée d'une révélation au grand jour de l'identité de YHWH est un leitmotiv dans la Bible. Quant aux racines métallurgiques, elles ne sont pas ouvertement annoncées dans la Bible, mais nombreuses sont les indications qui en suggèrent l'existence. Certaines d'entre elles sont présentées dans ma conférence.

La première partie de l'exposé met en évidence une dimension métallurgique à travers la représentation de l'univers céleste dans la vision inaugurale d'Ézéchiel (Ézéchiel 1). Celui-ci apparaît, en effet, comme un fourneau de métallurgie duquel une lumière intense émane depuis du métal en fusion (le fameux hashmal). Par ailleurs, le volcanisme est appréhendé par de nombreux prophètes comme le mode d'action privilégié de YHWH, et même sa théophanie. Cette imagerie est a priori singulière, étant donné que le volcanisme est inexistant à l'époque historique dans le pays de Canaan. Par contre, cette référence au volcanisme peut s'expliquer par un symbolisme spécifiquement lié à la métallurgie, cette activité étant la seule conduisant à une fusion de la roche assimilable à une coulée de lave. Cette association est confirmée par l'usage du souffle produit par YHWH pour stimuler cette activité volcanique. De même, certains textes bibliques indiquent que le nez et les narines de YHWH, des « organes » d'importance dans la régulation du mode opératoire divin, 
sont des appellations données respectivement aux tuyaux et embouchures de la soufflerie divine.

La seconde partie de l'exposé examine dans quelle mesure ce fondement métallurgique, apparemment enraciné dans des traditions sud-levantines de l'âge du bronze, est préservé dans la religion d'Israël. La représentation volcanique de la théophanie de YHWH au Sinaï, l'importance du volcanisme dans l'eschatologie biblique ou encore l'abondante imagerie métallurgique associée au mode d'action de YHWH, tous révèlent une surprenante conservation de la dimension métallurgique du yahwisme en Israël. Cette conclusion est confortée par l'abondance de cuivre dans le temple de Jérusalem et le symbolisme métallurgique qui est associé à la « mer de cuivre » et aux colonnes positionnées à l'entrée, nommées Boaz et Yakhin. Particulièrement parlant est le revêtement de cuivre de l'autel des sacrifices, caractéristique inhabituelle dans l'Orient ancien. Ce revêtement produisait apparemment un rayonnement thermique lors de la combustion des sacrifices d'holocaustes, ce même rayonnement lumineux signalé par Ézéchiel dans sa représentation du fourneau céleste, assimilé au kābôd (la "gloire » de YHWH) et émanant du métal en fusion.

Enfin, la troisième partie de l'exposé illustre en quoi les réformes du culte attribuées aux rois judéens Ahaz, Ézéchias et Josias ont contribué à l'érosion de la dimension métallurgique du yahwisme en Israël, et ce au profit d'un culte bien plus «classique » au Proche-Orient. Cette métamorphose apparaît dans les écrits bibliques identifiés avec l'école deutéronomiste, ce qui explique leur distance relative par rapport aux racines métallurgiques du yahwisme. Mais, paradoxalement, certains écrits bibliques datés de la période post-monarchique affichent une tendance contraire, à savoir une recrudescence de la dimension métallurgique. C'est notamment le cas pour les écrits affiliés à l'école sacerdotale. Cette orientation est par ailleurs fréquemment accompagnée d'une critique de l'effacement délibéré de la dimension métallurgique du yahwisme originel par les réformateurs du culte qui opérèrent à la fin de la période monarchique, effacement tenu pour responsable de l'abandon par YHWH de son peuple à la chute de Jérusalem. 